\title{
A salutogenesis approach to ageing with impairment: the managing and coping experiences of older people ageing with deafblindness
}

\begin{abstract}
An understanding of the psychosocial impact of deafblindness on older people is impoverished by a dearth of research in the field. Particularly limited are studies adopting a salutogenesis perspective, in which older deafblind people's coping capacities are explored. Much research focuses on vulnerability to unfavourable outcomes, which may perpetuate negative stereotypes of deafblind people as passive and dependent. Identifying deafblind people as a vulnerable group gives rise to misunderstanding of the impairment, perceptions of incapability, and neglect of deafblind people's agency. This paper draws on data from the first United Kingdom based study of vulnerability from the perspectives of older adults ageing with deafblindness. Findings presented here relate to participants' experiences of managing and coping with their felt vulnerability and ageing with deafblindness. The study adopted interpretative phenomenological analysis (IPA) as its qualitative approach. In-depth semi-structured interviews were undertaken between October 2014 and July 2016 with eight participants, aged between 48 and 83 years. Data were analysed using an iterative six-step IPA process. Three superordinate themes were identified: taking action to protect self; psychological coping strategies; accessing and using care and support. Participants' managing and coping strategies, and the care and support they value, respond to elements identified as generating felt vulnerability. Professionals should seek to bolster coping capacity and provide support in ways valued by those ageing with deafblindness.
\end{abstract}

\section{Keywords}

deafblindness, ageing, salutogenesis, interpretative phenomenological analysis

\section{Introduction}

Sometimes termed dual sensory loss, deafblindness is a complex condition (Bodsworthet al. 2011). It has multiple causes, though all result in impairment in the distance senses: vision and hearing (McInnes 1999). Deafblindness affects people in different ways, depending on whether the condition is congenital or acquired (Dammeyer 2014). Factors such as age, age of onset and the presence of co-morbidities also affect people's 
experiences of the impairment (Simcock and Manthorpe 2020). In the United Kingdom (UK), older people with late-life acquired deafblindness form the largest 'sub-group' of the deafblind population (Robertson and Emerson 2010) and there is research consensus that prevalence rises with increasing age (Wittich and Simcock 2019). Though they are a smaller sub-group of the deafblind population, people ageing with deafblindness have been identified in English policy for several decades (Department of Health 1997), but there is still little known about their lives (Simcock 2017a).

Deafblindness has a considerable psychosocial impact on those older people affected (Wittich and Simcock 2019). This includes functional difficulties with communication, mobility and access to information; that are central to the definition of deafblindness adopted in English social care policy guidance (Department of Health 2014). People ageing with deafblindness experience continual change and the consequent need for adaptation, similar to those ageing with various conditions, and some report that living with the condition for a long time does not make it any easier (Simcock 2017a). Nevertheless, understanding of the psychosocial impact of deafblindness on older people is impoverished by a dearth of research (Brennan and Bally 2007). Covering this small field, Kyle and Barnett (2012) argue that its focus on risk, insecurity and vulnerability to unfavourable outcomes supports a stereotyped view of deafblind people as a dependent population. This identification of deafblind people as a vulnerable group gives rise to persistent misunderstanding, a perception of incapability and the neglect of deafblind people's agency, creativity and ability, resulting in overprotection and control (Simcock 2020). A systematically conducted review exploring deafblind people's vulnerability found significantly less exploration of capacity to cope in material originating from the UK, North America, Australia, the Nordic countries, and central and southern Europe (Simcock 2017b), despite strengths, assets and ability to cope being key concepts in existing analyses of vulnerability, including vulnerabilities in old age (Brown, Ecclestone and Emmel 2017, Schröder-Butterfill and Marianti 2006). This reflects Danermark and Möller's (2008:S121) assertion that what is absent:

in the scientific literature on deafblindness is a salutogenesis perspective, i.e. research demonstrating the potentiality among people with deafblindness. 
Addressing this gap, this paper draws on data from the first UK based study of vulnerability from the perspectives of older adults ageing with deafblindness. The study adopted a salutogenesis orientation: an approach emerging from the stress and coping model originally devised by medical sociologist Aaron Antonovsky (Antonovsky 1979). In contrast with pathogenic approaches, which focus on the causes of disease, salutogenesis is concerned with factors that support and promote health (Mittelmark and Bauer 2017). Over the last three decades, research on salutogenesis has strengthened its evidence base (Lindström and Eriksson 2010). Its development has seen the emergence of a salutogenesis orientation in scholarly activity beyond the 'health arena' (Mittelmark and Bauer 2017) and various theoretical concepts in social sciences and social work research now fall under 'the salutogenesis umbrella' (Eriksson and Lindström 2010). These include: self-efficacy, hardiness, coping, resilience and quality of life (Lindström and Eriksson 2010). Essentially, as an academic orientation, salutogenesis adopts a positive perspective by focusing on factors that protect and promote well-being. As such, this study explored the coping and managing strategies of those ageing with deafblindness. The findings presented here show how participants make sense of their experiences of managing and coping with their felt vulnerability and ageing with impairment. Although deafblind people may be objectively categorised as 'vulnerable' owing to their impairment (Simcock 2017b), 'felt vulnerability' refers to the lived experience of the phenomenon.

\section{Methods}

As little is known about the experiences of deafblind people, there are calls for more qualitative research in the field (Jaiswalet al. 2018). With phenomenology, hermeneutics and idiography as its theoretical foundations, interpretative phenomenological analysis (IPA) is a qualitative approach to inquiry that facilitates a detailed and nuanced analysis of lived experience (Smith, Flowers and Larkin 2009). IPA was chosen as the most appropriate qualitative approach, being primarily concerned with lived experiences (Shinebourne 2011) and suited to studies of so-called 'vulnerable groups', privileging and giving voice to participant perspectives (Loo 2012). A limitation of research involving deafblind people has been the homogenisation of the deafblind population (Dammeyer 
2015). IPA's commitment to idiography ensured that variation between participants was highlighted (Smith, Flowers and Larkin 2009), responding to this critique.

\section{Participants}

Participants were purposively sampled. Though there is significant heterogeneity within the deafblind population (Dammeyer 2015), IPA studies ordinarily focus on a homogeneous sample (Smith, Flowers and Larkin 2009). This study therefore focused specifically on people ageing with the impairment, irrespective of aetiology. This choice responds to knowledge gaps and calls for further research on the experiences of this subgroup (Simcock 2020). Inclusion and exclusion criteria are listed in Table One.

$<<$ Insert Table One about here>>

In their systematic review of recruitment interventions used to recruit participants from vulnerable populations, UyBico, Pavel and Gross (2007) conclude that the effectiveness of a recruitment strategy is setting and population dependent. Consequently, to ascertain appropriate recruitment strategies, methods adopted in other studies with older deafblind people and in other IPA research were identified. Combined strategies emerged as the most successful approaches. To raise awareness of the study, information was shared with the two major UK deafblindness charities, one of which offered the opportunity to include a 'call for participants' in its monthly publication. Professionals and deafblind individuals well known and respected in deafblind organisations and communities, and with whom the first author had an existing professional relationship, were then contacted with a request for support with the recruitment process. Reflecting Latchem's (2016:7) observation that recruitment can be 'more participant-led than... one way', one participant contacted the first author directly with a request to be involved, having heard him speak at the 2015 Deafblind International World Conference.

Nine people expressed interest in participating in the study and all were sent further details about the research, in an appropriate format. Padgett (2008) observes that stereotypical views about the ability of those with particular conditions to offer personal accounts in interviews have been challenged by the experiences of qualitative researchers. Reflecting the principles of the Mental Capacity Act 2005 (England and 
Wales), those expressing an interest in the study were not therefore excluded on the basis of diagnostic label: the first author met all potential participants to determine capacity to provide informed consent and ability to offer a detailed first-person account as required in IPA research. Of the nine people expressing interest in participating, a total of eight participants fulfilled the inclusion criteria and were recruited to the study. All participants were white British, and aged between 48 and 83 . Though the study focused predominantly on older people, the decision to include those under 65 was in response to the paucity of research on the experiences of those ageing with, rather than into, a range of impairments, including deafblindness (Simcock and Manthorpe 2020). There were four women and four men. The age, aetiology of deafblindness, language and communication methods of the participants are listed in Table Two.

$<<$ Insert Table Two Here $>>$

\section{Ethical Considerations}

A participant information sheet (PIS) was sent to those interested in the study, in a variety of formats: standard, large and extra-large print (Arial point 12-26), Grade 1 and Grade 2 Braille, Moon (a tactile reading form devised by William Moon in 1845), audio, and a video in British Sign Language (BSL). This PIS described the study and its purpose, explained what participation involved, made it clear that people were under no obligation to be involved, and described the potential benefits and risks of taking part. Participants' voluntary informed consent to take part was confirmed by their signing the consent form or by consenting in speech or BSL, which was video recorded. Participants' anonymity is maintained by using pseudonyms and omitting some biographical details, as recommended when working with minority populations (Liamputtong 2007). To preserve confidentiality, interview recordings and documents containing participants' details were stored on an encrypted and password-protected USB flash drive. Participants were advised that a position of 'contingent confidentiality' was adopted in the study: confidentiality would be maintained unless they disclosed that they or someone they know was being or was at risk of abuse, neglect or harm, when the researcher would inform relevant services. No such disclosures were made during the study. 
As many deafblind people have limited social networks (Mar 1993), careful attention was paid to 'boundary maintenance' (Padgett 2008:77). The first author drew on his professional social work experience to explain boundaries and withdrew from researcher-participant relationships appropriately. This involved ensuring that participants had a full understanding of what participation in the study involved, and engaging in neutral phatic or social pleasantry form of communication at the beginning and end of interviews, in order to avoid what Wadsworth (1984) describes as a 'data raid' or 'smash and grab' approach. Recognising that participant trust in interviews necessitates boundaries that are 'permeable' (Thurairajah 2019), the decision whether or not to self-disclose personal information was not fixed, but flexible, depending on the situation and relevance to the topic. During some interviews, the first author offered 'complementary reciprocity' (Johnson and Rowlands 2012:104); this involves the sharing of information rather than disclosure of one's own experiences, ideas and thoughts. For example, participants were offered information about support and services for deafblind people. Although all participants expressed an interest in being informed about the outcome of the study, and some maintained brief contact after the interviews via e-mail, no difficulties relating to participant disengagement were encountered.

\section{Data Collection}

As arguably one of the best methods in IPA studies (Griffin and May 2012), data were collected via in-depth semi-structured interviews, which on average lasted 64 minutes (range 29 to 97 minutes). The total number of interviews completed was 18, as participants were interviewed on either two or three occasions, depending upon individual circumstances, as recommended by Padgett (2008). This supported the development of participant-researcher trust and rapport (Tarziaet al. 2013), and offered an opportunity to verify understandings of discussions in earlier interviews (Young, Ferguson-Coleman and Keady 2014) and to probe for further detail and more specific examples (Johnson and Rowlands 2012). Strategies for collecting rich data were adopted throughout the interviews and were adapted where necessary to meet participants' communication and language needs. The first author's experience as a specialist social worker, learning from a pilot interview, and the limited literature on the practicalities of interviewing deafblind people (Arndt 2010, Evans 2017, Oleson and Jansbøl 2005) informed these adaptations. British Sign Language (BSL) interpreters were employed to 
help facilitate interviews with two participants. The particular practical, epistemological and methodological challenges this involvement raised, and how these were addressed, are explored elsewhere (Bacchini and Simcock 2020, Simcock 2020). All interviews were video-recorded, in order to capture non-verbal communication, the visual expression of emotion and the responses of BSL using participants. The initial interview question combined enquiry about demographics with an open-ended tone: Please tell me about yourself. The remaining questions similarly adopted an open-question format, for example, 'Please tell me what 'being vulnerable' means to you' and 'Please tell me about a time you felt vulnerable'. Immediately following each interview, reflections were written, documenting contextual information and initial impressions of the encounter.

\section{Data Analysis}

All 18 interviews were transcribed verbatim by the first author, and a note made of initial thoughts on the interaction during this process, as recommended by Smith, Flowers and Larkin (2009). As BSL has no written form, the notion of a verbatim written transcript which accurately represented two participants' expression and meaning was problematic (Young and Temple 2014). Using an approach similar to that described by Arndt (2010) in her interviews with deafblind students using American Sign Language, the first author produced an 'interim' transcript by watching and re-watching the video recordings of the interviews. These interim transcripts were not solely a record of the audible, spoken English words of the interpreter, but drew on careful observation of the participants' signs and the first author's own knowledge of BSL. The interim transcripts included queries and tentative corrections of the interpreters' translation, recorded in red type font. As qualitative researchers must ensure that participants' perspectives are accurately represented (Regmi, Naidoo and Pilkington 2010), the first author then met with the original interpreters, and reviewed the videos and 'interim' transcripts. The interpreters were registered, qualified and had additional experience and skills in tactile communication, and were thus able to recognise linguistic differences between visual signed language and signed language received and expressed through the tactile modality (Collins and Petronio 1998, Dammeyer et al. 2015, Mesch 2001, Schwartz 2008). Therefore, in addition to responding to queries and correcting translation errors, interpreters also paid careful attention to conceptual equivalence and nuance of meaning 
(Berman and Tyyskä 2011). Reviewing the interim transcripts in this way reduced the risk of translational error, thus enhancing credibility of the findings (Squires 2009).

Analysis then followed the iterative six-step IPA process described by Smith, Flowers and Larkin (2009). First, written transcripts were read and re-read, and where the interviews had been conducted in BSL, video recordings were watched and re-watched with the interpreters. An exploratory commentary on a hard copy of each transcript was then prepared, using three analytic tools: descriptive comments; linguistic comments; and conceptual comments. Smith et al (2009) recommend working with hard copies as it enables close engagement with the data. In this study, this brought the added advantage of making it easier to review video recordings whilst simultaneously viewing a printed transcript. Themes reflecting both the participants' expressions and interpretations of these were then developed, as patterns and relationships within the transcript and exploratory notes were identified. To maintain IPA's idiographic commitment, analysis was completed for each participant individually before moving on to the next participant's dataset and then looking for patterns across 'cases'. Finally, connections and relationships between the themes and super-ordinate themes across all participants were identified. Throughout the analytic process, a record of thoughts, interpretations and decision-making was maintained.

\section{Findings}

Three superordinate themes were identified: taking action to protect self; psychological coping strategies; and accessing and using care and support. Reflecting IPA's 'interplay between the interpretive activity of the researcher and the participants' account of ... experience' (Eatough and Smith 2006:120), findings are presented as a narrative account and use extracts from interview transcripts to provide evidence for each theme. Where words contained in the interpretative account are in italics, these are also the direct words of the participants. Use of the symbol (I) immediately after direct quotations indicates that the words represent an English translation of signed language. 


\section{Taking Action to Protect Self}

All participants are active in seeking solutions and protecting themselves when in vulnerable situations. Although each uses various strategies, data reveal shared approaches: telling, educating and challenging others; responding to and managing risk; maintaining connection; using reserves; self-care; maintaining control; and demonstrating self as capable.

\section{Telling, educating and challenging others}

For Anthony, educating others is 'the gift of my deafblindness'. Like him, participants described telling people about their impairment, their communication needs and how best to assist them. When travelling by aeroplane, Anthony explained how he educates cabin crew:

I tell the crew about communicating, about writing on my hand. When my food is here, please indicate that by tapping on my shoulder (I).

A primary function of telling and educating is to enable people to understand both the participant and deafblind people generally. Faye explained that she tells people about her deafblindness, as she does not 'want there to be any misunderstanding'. Telling others also operates as a way of preventing misinterpretation of behaviour. Rose has difficulty seeing in inclement weather, owing to glare off wet road surfaces and raindrops on her spectacles. She therefore chooses not to go out in the rain, but explains this decision to others:

I'm quite open telling people that, but don't expect me to be, to appear when it's pouring with rain... I say, 'I'm not afraid of the rain', I, I tell them why, exactly why... And people seem to understand that.

Rose also described having to explain in order to challenge people's disbelief about the extent of her impairment. Unable to judge the height and depth of steps she focuses her vision on the sidewall, rather than the steps themselves, in order to descend safely. Observing her doing so on a university campus, fellow students questioned the extent of her sight loss, leaving her feeling the need to explain:

Some of the students, my fellow students, were walking behind me, and they said, 'You didn't even look, watch where you were going when you were going down the steps'. So, I explained this all to them. 
Telling others is something participants felt they 'have to do'. For Rose, although 'there was a time when I wouldn't have enjoyed it much', now older she is 'not afraid to tell people'. Nevertheless, telling people once is insufficient. Phillip described having 'to keep on explaining' and Anthony lamented that he needs 'to tell them again and again'.

Participants adopt different ways of educating others. Mike taught local college students about deafblind people and their needs. Some have shared written information, published by specialist charitable organisations, while some tell individuals about their impairment, its extent, and associated needs directly, in specific encounters:

I always have great difficulties, as I've said before, recognising people outside... I ask people to just to bear in mind that when they meet me out in the street or whatever, that, that they have to make the first move (Rose).

I might just... say, 'Look, you know, I'm severely sight impaired, not partially sighted. I can only see light and shade' (Phillip).

Phillip also makes use of equipment. This includes waving his red and white cane in the air, or more subtly:

I'm in a restaurant... Somebody comes up to me and says, 'Could you pass this over?' I said, 'What? What?'. 'Can you pass', you know, and then I go [rolls up sleeve and feels braille watch]. Don't have to say anything then [feels braille watch a second time].

Sometimes participants challenge others, standing up for themselves and demonstrating their ability to withstand threat or challenge, diminishing felt vulnerability. Caroline directly challenged a stranger who grabbed her arms to offer unrequested help, by telling him to 'get out of my space'. Rose recalled showing courage when challenging her parents about the support they offered, which was experienced as over-protection. This courage was also evident when Rose chided a staff member at a railway station, who was unhelpful as she tried to purchase a ticket with a credit card:

He kept saying things to me, which I obviously wasn't grasping quickly enough, and then he got really impatient and really, err, he said, 'I told you what to do that for' [mimics annoyed voice] and I, and at the end of it all, I said, 'Well, I don't think you've treated me very well'. I said, 'I am both sight and hearing impaired'.

Participants also challenge others by raising concerns or making formal complaints. For example, Mike raised concerns about staff with their seniors at his supported 
accommodation scheme, and reported that this makes him 'feel happy after a while'. More formally, some had written letters of complaint.

\section{Responding to and managing risk}

Participants' responses to and management of risk are important, and involve the identification of risks, consideration of the likelihood of harm, and calculating whether taking the risk is 'worth it'. In relation to being a victim of crime, although being 'always aware of these risks', Rose considers them low probability. They therefore do not prevent her going out alone:

... it doesn't stop me wanting to go out on my own... I don't think, Oh dear maybe if I go... somebody'll trip me up and grab, grab my handbag... obviously I'm aware of it, of the possibility of it. But it doesn't stop me from doing things.

Faye similarly evaluates risk when making decisions about travel:

I [pause] would not normally travel on my own at night, but there might be certain easy journeys that I would do... if I felt reasonably confident about the route.

She explained that she is now 'much more careful' when walking outdoors, particularly on steps and stairs. This involves slowing down, because the risk of bumping into things means being hasty is 'not worth it'.

Anthony described knowing about his 'own safety' when travelling, and refuted others' assessment that he is at risk owing to his deafblindness. Demonstrating his own understanding of risk, and frustration at the assessment of others, at the end of his second interview he mockingly commented on the interpreter touching him when engaged in tactile BSL:

I'm going to tell the police about him [interpreter] touching me [laughs]... [direct to the interpreter] maybe I'm at risk and should tell the police about the touching [laughs] (I).

Once risks are evaluated, some participants eschew certain tasks or situations as a way of managing them and avoiding or withstanding felt vulnerability. For example, going out at night, social events and certain domestic tasks are avoided. Nonetheless, Faye interpreted such an approach as 'taking an easier path' and expressed regret that this has, on occasions, left her foregoing opportunities similar to Caroline, for whom social isolation is increased by her avoidance of certain situations. Therefore, her risk 
management strategy sometimes involves taking 'things a bit more face on'. Reflecting on the likelihood or severity of potential harm, she asks herself, 'how bad can it get', as illustrated when describing her decision to go out for a pub meal with friends:

... it did worry me, but this time I thought 'well I'm gonna go out and enjoy myself'. I'm with friends, you know, how bad can it get? And erm, [pause] it, it, it was all really nice.

Matthew and Celia both reported systematically locking doors and checking the security of their homes each evening. Celia contrasted handling her money when with her communicator-guide compared to her daughter:

With the communicator-guide, I always put my coins in the purse, and pay the bill and then put it away in my bag. But with my daughter, I don't mind, because I always trust my daughter (I).

Such descriptions reveal how participants also adopt actions of a more practical nature to manage risks.

\section{Maintaining connection}

Although social situations are settings in which participants can feel vulnerable (Simcock 2020), maintaining human connection provides access to information about the world and reduces isolation and felt loneliness. Anthony described the curative effect of human contact, which is 'like a medicine for loneliness' and helps him 'feel part of the world'. Participants reflected on the importance of their friendships and make use of mainstream technology to stay in touch with friends. For some, this is used in conjunction with specialist equipment, such as braille output machines or speech software. Mike described active engagement with the local Deaf club, which offers a sense of belonging, and excitedly recounted social occasions he has enjoyed.

For Anthony, physical contact is an essential part of human connection. Touch enables him to 'feel human and like a real person'. Its importance to him is movingly captured in the following extract:

When I am on my own, like [pause] food for instance, I get a food delivery, somebody carries the food and puts it in the kitchen, and they obviously have to hold my hand to show me where it is, and for a few seconds, it feels good to have that human contact... Even though it's just this short, short moment, it's good to have contact (I). 
Anthony uses his artwork to maintain connection. Referring to a small statuette replica of Michelangelo's masterpiece David in his bedroom, he explained how this artwork maintains physical, human connection:

Many times I am on my own here, and I can't go out... What I do is, I have the statue [moves both hands over the statue, feeling it] and I can feel, and it helps me to feel human contact, through the statue, like touching a person... It's not a person; people might think I'm crazy... It kind of feels, well, I touch it [feels statue] and then I touch my own body [moves hands down torso] and it kind of feels like me... You have to find alternative ways to kind of engage with the world (I).

In this particularly poignant moment, Anthony highlighted his substantial creativity in developing coping strategies.

\section{Using reserves}

Participants described drawing on existing reserves in order to withstand challenge and thus reduce felt vulnerability. Such reserves include prior learning and experience, residual senses, and activities that develop physical strength. Faye, for example, described how previous experiences act as a 'learning curve', informing her approach to managing risk. Matthew and Anthony described acquiring attributes from their parents, which now support them in later life:

I'm too laid back for some of this stuff [pause] because it's the way I'm made, cos I take after, I think I take after my dad (Matthew).

My father did give me a lot of wisdom... he'd say please forgive me I don't have the education... He was very considerate, very considerate my father. And he had his own weakness... I want to help people... to understand that everyone's not perfect, and, but you should accept what people have (I) (Anthony).

Reflecting his father's considerate nature, Anthony has acquired a sense of forgiveness, as he accepts the limitations of both himself and others.

Participants with residual hearing and vision described making best use of them. Residual hearing and vision help Rose and Celia mobilise safely outdoors. Caroline and Anthony, having been sighted in earlier life, described making use of their visual memory. Now experiencing total sight loss, Anthony makes greater use of touch, as does Mike. Caroline illustrated how the expansion of her vocabulary though reading, supports her lip-reading abilities: 
a lot of that kind of, of understanding what's been said, depends on your own reading, the amount of reading you've done, your own vocabulary and how extensive it is. Because you do, you do a lot of gap filling.

Phillip described the multiple benefits, both physical and mental, of Tai Chi:

I have noticed erm balance, posture, circulation, and muscle tone is all improved...So, if I'm on a bus and the bus jolts, and I'm standing up, without smashing my head against something, falling down or something, I can reassert my body in such a way that I have control of my movements.

These benefits appear to act as a reserve that helps him withstand difficulties encountered when travelling on public transport.

\section{Self-care}

Engaging in self-care helps participants manage difficulties associated with ageing with deafblindness and withstand challenge. Reflecting their individuality, participants selfcare in several ways: engaging in hobbies and sporting activities, gardening, maintaining a sense of humour, and meditation.

Although some described keeping themselves busy, others take time out. With increasing sight loss, Faye described reducing her working hours to have a 'breathing space', and Celia occasionally asks her daughters to 'leave me alone', when she is feeling anxious about increased sight loss and needs time alone to 'build up my strength'. For Matthew, metaphorically 'switching off' enables him to withstand the fear he feels in hospital settings:

I always take my, erm, MP3, plug in, plonk [mimes putting large headphones on] fine, shut out the rest of the world, cool.

When making sense of his coping strategies, Phillip asserted that 'it's the small things that matter'. He described the helpfulness of stroking his cat or having a coffee. Mike similarly explained how having been in situation of felt vulnerability, he feels 'happy again' when listening to music, having a coffee or smoking a cigarette. Small things also make a positive difference for Celia. Having been lost then anxiously finding her way to a police station, the impact of having a hot drink while awaiting her daughter to come and collect her was significant: 
When I arrived and I sat down, I was surprised he (Police officer) could sign. I was relieved, we were talking, signing, and writing a little bit. He asked me if I wanted a cup of tea. I said, 'Yes please'... that's where I sat having my cup of tea. It was lovely (I).

\section{Maintaining control}

Participants described feeling vulnerable when they sense they are out of control (Simcock 2020). In further interpreting their experiences, they described ways in which they seek to maintain control in their lives. This is enacted through various means: taking things step-by-step; making and acting upon their own decisions; using care and support in their own way; and engaging in preparation and planning.

To manage the challenges of ageing with deafblindness, particularly deteriorating hearing and vision, participants described addressing difficulties one at time. Faye recalled a particularly difficult time, which coincided with deterioration in her vision. To manage the situation she 'just put one foot in front of the other'. Caroline takes control of her deteriorating sight and hearing loss, by 'driving' the decisions associated with increased need for support:

I certainly don't ignore the deterioration of my vision or of my hearing.... I decided as well, I think I'd better start using the symbol cane. I decided we need to go to a long cane... I even decided that I would register blind... it was driven by, driven by me.

Making and acting on one's own decisions are important ways for participants to maintain control. This includes making decisions on who to tell about their deafblindness, and where to go socially when making use of informal support. Although Phillip has assistance managing his correspondence, he stressed that he decides 'what action should be taken'. Anthony demonstrated how he will challenge those who seek to control him:

If I'm excited, my voice is loud... I don't know but people are always telling me to 'shhhh', keep it down. I like to talk to people, I don't want to sit and do nothing. Some people maybe get embarrassed. Anyway, so, I was talking to people, and it was difficult because she thought she could control me, and I said, 'No, it's my decision to talk to people' (I).

Participants also make their own decisions about the timing, the type and whether to make use of care and support. This includes choosing when to make use of equipment, contact social care services, engage with rehabilitation, and disengage from day services 
and social clubs. Caroline asserts control by making her own choices throughout her life, even if contrary to professional advice. She recalled refusing to wear a body-worn hearing aid when a child and rejects the use of red stripes on her long cane:

... people have said to me, well you're hearing and sight impaired, you must put red bands on it, and I think, 'No, I mustn't, it's my choice'.

When participants do use care and support services, they do so in their own way. One way in which participants realise this, is by explicitly instructing those assisting them:

I don't want her to pressurise me to do what she wants. It's what I want. So, I've had that discussion with [communicator-guide] and that's fine (I)(Celia).

I'm the employer. I have to give them dates, times, a number of hours, rates of pay and invoicing, and make sure that it's clear and they understand. I decide everything. I tell you, you have to do it for me, you have to follow. You don't decide for me... It feels good, because I feel responsible... I never allow them to control me, no. When they work with me, then work with me, fine, control over me? No (I)(Anthony).

Participants also use equipment in their own way. This includes holding magnifiers uniquely, combining specialist and mainstream equipment, and developing their own techniques that differ from those taught by professionals:

I use that, not the way [rehabilitation officers] taught, because [pause] erm, because of my sight. So they say, tap it along the ground and all that [demonstrates using cane this way], I don't do that... I just, I just hold it, at an angle, level with almost, level, erm, at right angles like that [demonstrates positioning of cane] from the top to the ground... And it's the way I've always done it, and it works (Matthew).

Engaging in preparation and planning helps some participants maintain control. This can be preparation for specific short-term events or long-term eventualities. Matthew and Anthony described how they prepare and make plans before going into hospital, either for an outpatient appointment or for a short stay. This includes doing 'test walks' to become familiar with the route to the hospital department, and preparing information on communication methods to share with health professionals. Although he 'takes life as it comes', Matthew is planning for a time when his parents have died. He described having 'talked about it quite a lot actually over a little while'. Having a similar 'take life as it comes' philosophy, Rose asserted that 'we can't plan for the future' because 'we haven't got any ultimate control over it'. Nevertheless, she has prepared for the possibility of further deterioration in her hearing and vision, by learning alternative communication methods: 
I've not actually had to use it [deafblind manual], but at least I, I know I could bring it into ac-, action if I need to.

\section{Demonstrating self as capable}

All participants described feeling vulnerable when perceived as incapable (Simcock 2020) and all seek to contradict such perception by demonstrating their capability. This is enacted in the interviews themselves, as participants not only made broad statements about their abilities, but presented as eager to describe their skills, talents and achievements. This includes providing a 'good service' at work, being accomplished artists and musicians, travelling independently, being economically 'savvy', and chairing charitable groups. Anthony asserted that 'deafblind can do anything like everyone else can', and it was apparent that participants take pride in their achievements. Reflecting on a time she supported her husband through a period of ill health, Faye observed that 'it could have been quite easy to just have gone under with the strain' and she is therefore 'quite proud of what I've achieved'. In making sense of the experience of getting lost, having boarded the wrong bus, Celia made it clear where the fault lay, negating any notion that it is she who lacks competence:

The bus driver was stupid, because he forgot to change sign on the bus... I'm not stupid. I know, I do know (I).

Participants also demonstrated their capability during their interactions with other people. Matthew challenged the assumptions of fellow gymnasium goers who perceive him as unable to use the equipment:

I jump on the stuff and I think, oh yeah, fine, I'll do all that. And he looks at me and he goes, 'Oh God, he can'.

Anthony explained that he needs to 'convince' and 'help people to accept my capability' and does so by showing them how he cooks, irons, makes his bed, and paints pictures. For Rose, having to prove to others that she is capable has been 'a struggle with me all my life'. She explained how moving out of her parents' home to live independently was important in refuting their perception that she couldn't look after herself:

I managed to keep alive because I was so afraid, err, I managed to eat, so-, err, to [pause] to look after myself, because I knew I had to because I didn't, I want, I didn't want... Err, prove that, you know, that they were right, that I couldn't look after myself'. 
In her qualitative study involving 27 deafblind individuals, Hersh (2013) notes that deafblind people are not only recipients of care, but also care providers. Participants in the current study similarly demonstrate their capability by helping others, in various ways. This includes leading community projects and volunteering for charitable organisations, and offering individual care and support. Rose recalled supporting her lodgers, some of whom had mental health problems, and Anthony described giving other deafblind people 'advice'.

\section{Psychological Coping Strategies}

In addition to the practical actions, participants adopt psychological strategies. The strategies vary, but are centred on three approaches: accepting things that cannot be changed; changing one's own response; and demonstrating tenacity.

\section{Accepting things that cannot be changed}

Some participants described feeling resigned to things and having no regrets, irrespective of life's vicissitudes. Matthew made repeated reference to 'taking life as it comes', stating somewhat stoically that he 'could be here today and gone tomorrow'. Anthony presented a similar perspective visually, showing a self-portrait during his first interview, he described as representing his life as both 'beautiful and struggle, yet real'.

Acceptance enables participants to cope with different aspects of their lives: deafblindness itself; difficulties associated with the impairment; specific situations such as being alone, having to attend regular hospital appointments, and the reduction of formal care and support; getting older; and others' unwillingness to communicate. Anthony described learning to accept himself, declaring that 'I am who I am'. He explained that this has enabled him to accept others, seeing no one as perfect, and therefore avoiding a sense of blame when they misunderstand him or are unable to meet his needs: 'I always try to understand that it's not people's fault'. Reflecting on her experiences of being misunderstood and perceived as incapable early in life, Rose comparably avoids blaming her parents and her school, acknowledging that 'they did the best they could and it was nobody's fault'. 


\section{Changing one's own response}

Although others' responses can create felt vulnerability (Simcock 2020), participants' own responses can influence the experience. For example, Celia described 'changing her way of thinking' when becoming distressed or anxious as she imagines further deterioration of her vision. Despite her concerns about the future being emphasised throughout the interviews, the impact of a change in thinking is apparent in her final reflection:

In the past, there was no awareness of Usher, but now it's improved, people try to help. So, the future, hopefully, that will get better for me (I).

Other participants described changing their ways of thinking, particularly negative thoughts about further deterioration in vision and hearing. They avoid over thinking or pondering on the matter, and 'try to think about good things'. Both Anthony and Faye avoid thinking 'why me':

... sometimes you think, 'I could just do without this', you know, just [shakes head] 'why, why do I have this' sort of thing, but, err, not too much of that (Faye).

Reminiscing about negative childhood experiences, Rose explained how now, as an adult, she sees them 'in a different light'. This has enabled her to better understand these experiences and prevents her from seeing herself as at fault. For example, her perception of being 'a liability' at school, is now interpreted differently:

... there was quite a lot of discrimination and what we would now call bullying, but we didn't, it wasn't recognised as bullying in those days... Erm but I realise now that's what it was.

Participants also described how changing their response in particular situations can diminish their felt vulnerability. For example, Anthony endeavours to 'stay relaxed' at times of difficulty. He recalled a time when he was left alone overseas, following a disagreement with his communicator-guide resulting in her return to England. Staying relaxed and accepting it are important to Anthony, as he manages situations within which he would ordinarily feel vulnerable:

I managed myself, I kept calm. I think it's very important to always keep calm and not panic. So, you just have to think things through. When she left me on my own, I just made different plans. That was a bad experience... but I was fortunate, FORTUNATE [finger spelled], stayed calm, accepted it (I).

Now older, Rose has changed her response in situations where she is unable to hear conversation. When younger, she avoided telling people about her hearing loss, fearing 
a negative reaction, and instead sought to 'disguise the fact'. Believing hearing loss is now better understood and less stigmatised, she is more open to telling others, removing the need to 'bluff my way through'.

\section{Tenacity: keeping going}

Describing themselves using words such as 'strong' and 'determined', some participants understand their ability to withstand challenge as tenacity: they just 'keep going'. Matthew explained how he just 'gets on with it' and 'carries on'. Recalling a period of serious illness in addition to deafblindness, Rose asserted that 'one way or another, I've coped with that'.

Participants keep going because they believe there to be no alternative or because of a felt sense of obligation. Faye described independently managing a difficult situation at home, despite her deafblindness, because she 'didn't really have that much of a choice'; as she reflected on a possible future without her husband, her felt obligation to keep going is revealed in her observation that 'you just have to':

I don't know what I would do, but I think probably, I hope that I would pick myself up, and I would just carry on, I would, you just have to don't you?

Caroline judged a failure to keep going as 'immoral', because 'you're letting people down'. It is therefore important for her 'to soldier on':

Because there isn't anything to look forward to. There's... deteriorating sight, deteriorating hearing, dementia, infirmity, several types of cancer, stroke, heart attack, erm, being on your own. So, what's there to look forward to? Not a lot. But erm, I just keep going.

Even during her bleakest moments, Caroline will 'just keep going'.

\section{Accessing and Using Care and Support}

Times when the support upon which one relies is unavailable engender felt vulnerability among participants (Simcock 2020). This final superordinate theme shows how participants described making use of care and support, and regarded it positively, emphasising the role its presence or absence plays in the vulnerability experience. In developing their reflections, they identified the attributes of valued and effective support, and described the type of support they desire in the future. 
Participants use a range of formal support, including personal assistants (directly employed care workers) and communicator-guides funded by local authorities. Some care and support is provided informally. This includes that from family and friends, and from faith communities. Phillip explained how he receives help from an acquaintance:

... always helps me, the lovely... man who comes to the bus stop, he takes me to the shops... And he's very kind to me... he helps me with the bus stop, which is nearby... he takes me out [of the café] when I've finished... he'll take me to the traffic lights and help me across the road.

Some participants also make use of aids and equipment, including specialist and mainstream equipment and technology. Mike explained how he combines equipment and human assistance to mobilise safely, holding on to arm of a sighted-guide, while using his long cane. Phillip similarly combines equipment and human support to access his computer:

... all my computer work is done over the telephone, I use headphones connected to the telephone. And I have a computer assistant at the other end of the line.

Though participants reported some limitations with equipment, their care and support are highly regarded. Participants described the support they receive as 'fantastic', 'wonderful' and 'very good'. For Phillip, mobility training from rehabilitation officers is 'vital, essential'. The impact of support on participants' well-being is also important. Celia reported that having communicator-guide support has made 'a big difference' and that she now feels 'much happier... much better'. Participants also described support 'taking the pressure off' and making things 'easier'. Support has a role in helping participants not only complete tasks but also enjoy life. For Matthew assistance from his parents makes walking outdoors more enjoyable, and enables him to do more than just the basic cooking he can manage alone:

...they look around for all the, all the hazards and I don't have to look around for all the hazards... I just bounce along... quite happily [smiles]... when I've done, erm, what I call 'high cooking' as it were... I've had, I've always had, erm, assistance. 


\section{Attributes of effective and valued support}

Reflecting on their positive experiences of care and support, participants identified particular attributes that they understand as rendering this effective. These attributes negate factors contributing to felt vulnerability: in particular, support is effective when the individual is understood and maintains control. Understanding is demonstrated by the way others provide care and support. Describing her colleague alerting her to obstacles as she moves around the workplace, being understood appears as important to Faye as the assistance itself:

I think gosh she, she's got it [louder voice] she knows what I'm up against.

Providing help intuitively, instinctively and discreetly is also valued; in such situations, help does not need to be requested, as both the need for it and the way to provide it are understood. Rose recalled experiencing such assistance, as she finds herself needing support to navigate safely through a public house:

We went in to use, in to a pub to use the ladies... and it was a very bright and sunny like it is today, and immediately that lady... took hold of my hand and walked me through the pub, which was of course in semi-darkness anyway... I was so relieved she did that because I wouldn't have been able to see a thing... I couldn't have managed without it, but I didn't have, even have to ask her to do it, she just did, automatically did it.

Although important, having an understanding of deafblindness and any associated needs is insufficient. Participants interpreted support as effective when they are understood and known as individuals. Rose reported that those who understand her, are those who 'actually get close enough to get to know me'. When people do, she described feeling better supported and respected. This is further illustrated in participants' experiences of positive support as relational. Describing how he interviews for new communicatorguides, Anthony did not comment on their understanding of deafblindness, but rather explained that he asks 'about their character' and then does a 'trial for a month to see whether we get on'. The importance of a good relationship is key to the effectiveness of the support offered by one of his current communicator-guides, with whom he is 'compatible' and 'harmonised':

The relationship with the communicator-guide... It's beautiful... And sometimes we argue, but we have a good relationship. Because she is not only a professional, she's a professional and a human, she is both. We get on very well (I). 
Support is deemed effective when it enables participants to maintain control: when it is provided in a way that does not negate their autonomy. Making use of direct payments from the local authority to fund his care and support, and therefore being an employer, supports Anthony and Celia to maintain control. Celia described how things are also 'the same with my daughter', as together they 'decide when to go out' and as such maintain 'control through discussion'. The way Phillip and Mike interpret the support they receive as enabling them to maintain control is revealed in the language used to describe it. Both explained that they receive help 'with' or 'work with' their personal assistants or support staff.

Flexibility is also important, and participants described valuing support that is available 'as and when'. Anthony explained, that when out socialising, 'the guide isn't with me' and that she only comes to him if communication support is required. Phillip and Mike described being flexible with their funded hours of support, frequently changing these to enable them to engage in events in which they are interested, as they occur.

\section{Desired future support}

Participants offered reflections on the type of support they hope for in the future. Those not currently receiving ongoing formal support, described being 'open to it' or giving it consideration. The type of support participants described being interested in varies. Nevertheless, data reveal certain attributes of desired future support: that which is relationship-based and flexible.

Anthony described wanting a communicator-guide whom he is 'able to relate with', and with whom he 'can share something'. Although ability to communicate effectively is discussed, Anthony does not prioritise this. He described kindness and empathy, arguing that 'what's important is that they are human first'. Comparably, when describing his ideal communicator-guide, Matthew did not refer to their knowledge of deafblindness or specialist skills, but rather their age, sex and personality. He imagines it being someone who is willing to 'stick up for' him. 
Emphasising their preference for care and support based on relationships, Caroline and Anthony reject what Anthony terms 'professional business', in which defined tasks are completed in exchange for funding, devoid of relational attributes:

I want to be able to relate to them... if [organisation] provide me with a guide, I make a list of tasks, so 'take me to the shop' or 'take me to the doctors or the dentist' maybe, and then, that's their job finished. I pay them, and off they go. And that's only business, that's just business. That's the professional business. My relationship, my feelings, maybe I feel lonely (I)(Anthony).

If you have, use a communicator-guide, you want somebody that you can empathise with or who will empathise with you... You don't just want somebody off the street, who just says give 'em seven quid (pounds) an hour and I'll erm walk round with you (Caroline).

Participants reported that the development of such relationships necessitates continuity of support and that they are known. Faye asserted that one needs to 'get to know me quite well to know what I'm dealing with', and Anthony stressed the requirement that he is known as a unique individual, purporting that 'they need to understand the depth of my soul'.

Flexibility is also an important element of desired future support. This is both temporal flexibility and that associated with functional boundaries. Matthew expressed needing support to be available when necessary and Rose expressed a similar desire:

I often think it would be quite nice to have someone, or just some, something you could err, as it were, switch on, that would fill in all the gaps for me when I need them.

Feeling vulnerable in situations of unplanned change, Matthew maintains a routine at home. Nevertheless, he explained how he would welcome support that could enable him to move beyond routine and be more spontaneous, taking him where he 'might not normally go to, for something a bit different'. Anthony believes realising this desire, which he shares, necessitates communicator-guides to 'do something that is outside of their boundaries':

If I ask... a guide, 'will you please, I don't know, take me to the pub?' And they say, 'Why?' 'Well maybe I want to find a person to have sex, because I can't have sex here, I can't meet someone for sex here'. So, for example, if I, if you were at home, you can have sex any time you want, but I can't (I).

It is clear that adhering to a list of defined tasks, which are within set boundaries, means that communicator-guides are not able to address all of Anthony's needs. 


\section{Discussion}

Pruchno, Heid and Genderson (2015) advocate that understandings of successful ageing be reconsidered. Rejecting the notion of the avoidance of ill-health or impairment as indicative of success, they present it instead as 'a pattern of resilient trajectories in response to adversity over the course of a person's life' (ibid.:204). This, they argue, acknowledges that those ageing with impairments can and do age successfully. Westwood and Carey (2018) contend that research involving those ageing with impairments can enhance our understanding of resilience and positive adaptation. A focus on resilience, rather than difficulties and problems, challenges negative perceptions of disabled lives as inherently vulnerable lives (Björnsdóttir and Svensdóttir 2008) and older people as a societal burden (Lloyd and Sullivan 2018). As such, the potential of research on ageing, and ageing with impairment in particular, that adopts a salutogenesis orientation is evident. Nonetheless, there is a paucity of research on deafblindness adopting such a focus.

There is a shared understanding of vulnerability among this study's participants as being primarily negative, but participants do not present as passive individuals: they are active in responding to and managing their felt vulnerability and the challenges they face. Combining these findings with those from a United States (US) qualitative study (Arndt and Parker 2016) and another from Sweden (Ehn, Anderzén-Carlsson, Möller and Wahlqvist 2019), helps build a picture of how deafblind adults actively and creatively respond to the challenges they encounter. Participants in each study represent diverse groups of deafblind people. In Arndt and Parker's (2016) study the ten participants were aged between 26 and 62 years, and were deafblind because of Usher syndrome (Type II or III), Ichthyosis or a condition unspecified. The 14 participants in Ehnet al. (2019) study were aged between 20-64 years and all had Usher syndrome Type II. Despite this diversity, comparable findings are evident, and show how deafblind adults use practical and psychological coping strategies.

Participants in the present study report how they maintain control in their lives, and 'being at the helm' is the term used by Ehn et al. (2019) to understand the principal way in which their participants manage life's difficulties. Similar to the present study, Ehn et 
al. (2019) also observe the role that telling and educating others about their impairment have in participants' coping strategies, and in both studies, this is described as essential, yet ongoing and not always effective. On occasions, in both studies, participants move beyond just telling and educating other people, and actively challenging them; the need to be assertive and stand up for oneself is described across all three studies.

Telling of their achievements, skills and talents, participants in the present study also explain how they demonstrate their capability to others. Such demonstration was similarly observed by Ehn et al. (2019) and, just as participants in the current study often reveal their competence through their support of others, Arndt and Parker (2016) report on the role assisting other people plays in their participants' sense of resilience. Nevertheless, participants across the studies not only care for others, but also for themselves. This includes self-care strategies, such as engagement in hobbies, escapism, having a coffee, and the use of humour; the latter is also observed by Högner (2016) in her study involving those with Usher syndrome. Self-care involves maintaining social and emotional connections with other people, and psychological strategies such as acceptance, positive thinking and tenacity. Although individual to their particular circumstances, participants in all three studies also describe drawing on available reserves: this includes wisdom gained from their parents, memories, and residual hearing and vision. Cullati, Kliegel and Widmer (2018) argue that the use of reserves has an important role in diminishing vulnerability in later life, but distinguish them from resources. Reserves are conceptualised as those things for future rather than immediate use. Rose's earlier learning of deafblind manual (a tactile communication method), illustrates the role of reserves conceptualised as such. Deafblind manual is not a communication method she needs to use now, but having learnt it already, she can bring it into action when needed. Finally, use of support also has a role in participants' lives, observed across the three studies. This includes engagement with formal, state funded and organised services, use of various aids and equipment, and support from family, friends and neighbours.

Ehn, Anderzén-Carlsson, Möller and Wahlqvist (2019) posit that their findings problematise the perception of deafblind people as vulnerable. What the present study shows is that the ways in which participants manage their difficulties resonate with the 
elements they identify as generating their felt vulnerability: being and feeling misunderstood; feeling unable to withstand; isolation; losing control; being misunderstood; and being perceived as incapable (Simcock 2020). The type of care and support they both value and desire is similarly observed to address the elements they interpret as contributing to their experiences of vulnerability.

\section{Strengths and Limitations}

Strengths of this study lie in its in-depth and individually tailored interviews, which met participants' language and communication needs, ensuring data accuracy, and therefore, trustworthiness of the findings. The credibility of the study is enhanced by the opportunities to interview participants two or three times, and the attention paid to analytical rigour. This study also has a focus on those ageing with deafblindness, a group marginalised in gerontological research and ageing policy (Simcock and Wittich 2019).

Although statistical representation is not the study's aim, the sample size is small. Furthermore, while all participants are ageing with deafblindness, they differ in other ways. Differences related to age, aetiology of deafblindness, and order and timing of onset of impairment may all impact on their experience. Nevertheless, IPA's idiographic commitment enabled exploration of the uniqueness of each participant. Limiting some biographical details of participants may affect evaluation of transferability of the findings, but was necessary to maintain anonymity.

Particular disadvantages faced by deafblind people from Black and Minority Ethnic communities are reported (Joule and Levenson 2008), but their roles in influencing experiences were not explored in this study, as all participants were white British. All were living in the community and were in contact with deafblind organisations. Though a known strategy to promote rigour in qualitative research, 'member checking' by sharing transcripts with participants or holding further meetings with participants was not possible in this study, owing to both resource limitations and the fact that BSL has no written form. 


\section{Conclusion}

An understanding of the psychosocial impact of deafblindness on older people is impoverished by a dearth of studies. Particularly limited in the literature is research adopting a salutogenesis perspective, in which consideration is given to older deafblind people's coping capacities. Such paucity risks perpetuating negative stereotypes of deafblind people as passive and dependent. Therefore, though there is scope for further qualitative inquiry into the experience of vulnerability among other sub-groups of the deafblind population, researchers should explore coping capabilities and strategies within any such study.

Participants in the study reported here adopt various strategies and demonstrate creativity as they develop solutions to the challenges they encounter. Though these differ among participants, the ways in which they manage their difficulties, and the attributes of the care and support they value, respond to the very elements they identify as generating their felt vulnerability. Professionals should seek to bolster coping capacity and provide support in ways valued by those ageing with deafblindness. Interventions that enable those ageing with the impairment to maintain control and demonstrate their capability are particularly important. Interventions shown to achieve such persondefined outcomes should thus be developed for this population, and assumptions of incapability based on impairment rejected.

\section{Statement of Ethical Approval}

The study was approved by the Health Research Authority Social Care Research Ethics Committee (Reference: 13/IEC08/0049).

\section{Statement of Funding}

Although not a funded study, the first author received funding from Staffordshire University and the British Association of Social Workers (Social Workers' Educational Trust) towards his doctoral studies. 


\section{Declaration of contribution of authors}

The paper presents findings from a study undertaken by the first author as part of his doctoral studies, and supervised by the co-authors. The co-authors commented on drafts of this paper.

\section{Statement of Conflict of Interest}

None

\section{Acknowledgements and disclaimer}

The authors are very grateful to the eight participants for so generously sharing their experiences, to the BSL interpreters involved in the study, and to the specialist organisations for supporting participant recruitment.

Disclaimer to be inserted. 


\section{References}

Antonovsky, A. (1979) Health, stress and coping. Jossey-Bass, San Francisco, CA. Arndt, K. (2010) Conducting Interviews with People Who Are Deafblind: Issues in Recording and Transcription. Field Methods, 23, 204-214.

Arndt, K. and Parker, A. (2016) Perceptions of Social Networks by Adults Who Are Deafblind. American Annals of the Deaf, 161, 369-383.

Bacchini, S. and Simcock, P. (2020) A Silent Minority, unheard and unseen? A reflective account of methodological and lingustic challenges in research with older people ageing with deafblindness. Expressio, 1, 147-166.

Berman, R.C. and Tyyskä, V. (2011) A critical reflection on the use of translators/interpreters in a qualitative cross-language research project. International Journal of Qualitative Methods, 10, 178-190.

Björnsdóttir, K. and Svensdóttir, A. (2008) Gambling for capital: learning disability, inclusive research and collaborative life histories. British Journal of Learning Disabilities, 36, 263-270.

Bodsworth, S.M., Clare, I.C.H., Simblett, S.K. and Deafblind UK. (2011) Deafblindness and mental health: psychological distress and unmet need among adults with dual sensory impairment. British Journal of Visual Impairment, 29, 6-26.

Brown, K., Ecclestone, K. and Emmel, N. (2017) The Many Faces of Vulnerability. Social Policy and Society, 16, 497-510.

Collins, S. and Petronio, K. (1998) What Happens in Tactile ASL? In Lucas, C. (ed), Pinky Extension \& Eye Gaze: Language Use in the Deaf Community. Gallaudet University Press, Washington D.C., 18-37.

Cullati, S., Kliegel, M. and Widmer, E. (2018) Development of reserves over the life course and onset of vulnerability in later life. Nature Human Behaviour, 2, 2018, 551558.

Dammeyer, J. (2014) Deafblindness: a review of the literature. Scandinavian Journal of Public Health, 42, 554-62.

Dammeyer, J. (2015) Deafblindness and dual sensory loss research: Current status and future directions. World Journal of Otorhinolaryngology, 5, 37-40.

Dammeyer, J., Nielsen, A., Strøm, E., Hendar, O. and Eiríksdóttir, V.K. (2015) A case study of tactile language and its possible structure: a tentative outline to study tactile language systems among children with congenital deafblindness. Journal of Communication Disorders, Deaf Studies \& Hearing Aids, 3, 133-139.

Danermark, B.D. and Möller, K. (2008) Deafblindness, ontological security, and social recognition. International journal of audiology, 47, S119-S123.

Department of Health (1997) Think Dual Sensory: Good Practice Guidelines for Older People with Dual Sensory Loss. Department of Health, London.

Department of Health (2014) Care and Support for Deafblind Children and Adults Policy Guidance. Department of Health, London.

Eatough, V. and Smith, J.A. (2006) I feel like a scrambled egg in my head: An idiographic case study of meaning making and anger using interpretative phenomenological analysis. Psychology and Psychotherapy: Theory, Research and Practice, 79, 115-135. Ehn, M., Anderzén-Carlsson, A., Möller, C. and Wahlqvist, M. (2019) Life strategies of people with deafblindness due to Usher syndrome type $2 \mathrm{a}$ - a qualitative study. International Journal of Qualitative Studies on Health and Well-being, 14, 1-16. Eriksson, M. and Lindström, B. (2010) Bringing it all together: The salutogenic response to some of the most pertinent public health dilemmas. In Morgan, A., Ziglin, E. and 
Davies, M. (eds), Health assets in a global context: Theory, methods, action. Springer, New York, NY, 339-351.

Evans, M. (2017) Empowering People Experiencing Usher Syndrome as Participants in Research. British Journal of Social Work, 47, 2328-2345.

Griffin, A. and May, V. (2012) Narrative Analysis and Interpretative Phenomenological Analysis. In Seale, C. (ed), Researching Society and Culture. Sage, London, 441-458. Hersh, M. (2013) Deafblind People, Communication, Independence, and Isolation. Journal of Deaf Studies and Deaf Education, 18, 446-63.

Högner, N. (2016) Humor as a coping strategy for people with Usher syndrome. American Journal of Educational Research, 4, 1191-1196.

Jaiswal, A., Aldersley, H., Wittich, W., Mirza, M. and Finlayson, M. (2018) Participation experiences of people with deafblindness or dual sensory loss: A scoping review of global deafblind literature. PloS One, 13, 1-26.

Johnson, J.M. and Rowlands, T. (2012) The Interpersonal Dynamics of In-Depth Interviewing. In Gubrium, J., Holstein, J., Marvasti, A. and McKinney, K. (eds), The SAGE Handbook of Interview Research. Sage, London, 99-113.

Joule, N. and Levenson, R. (2008) People from Black and Minority Ethnic Communities and Vision Services: A Good Practice Guide. Thomas Pocklington Trust, London.

Kyle, J. and Barnett, S. (2012) Deafblind Worlds. Deaf Studies Trust and Sense, Bristol. Latchem, J. 2016. Troubling researcher-led recruitment: the self-selection of braininjured adults who lack capacity to consent. York Policy Review, 3, 1-11.

Liamputtong, P. (2007) Researching the vulnerable. Sage, London.

Lindström, B. and Eriksson, M. (2010) The hitchhiker's guide to salutogenesis:

Salutogenic pathways to health promotion. Folkhälsan Research Centre, Helsinki. Lloyd, L. and Sullivan, M.P. (2018) Ageing, ethics and social welfare: contemporary social work and social care practices with older people. Ethics and Social Welfare, 12, 201-203.

Loo, E.W.H. (2012) Evey contact leaves a trace: IPA as a method for Social Work research. In Fan, S., Le, T., Le, Q. and Yue, Y. (eds), International Conference: Innovative Research in a Changing and Challenging World. Australian Multicultural Interaction Institute (AMII), Phuket, Thailand.

Mar, H.H. (1993) Psychosocial Services. In Reiman, J.W. and Johnson, P.A. (eds), National Symposium on Children and youth who are Deaf-blind. Teaching Research Publications, Monmouth, OR, 42-60.

McInnes, J.M. (1999) A Guide to Planning and Support for Individuals Who Are Deafblind. University of Toronto Press, Toronto.

Mesch, J. (2001) Tactile sign language: turn taking and questions in signed conversations of deaf-blind people. In Prillwitz, S. (ed), International Studies on Sign Language and Communication of the Deaf. Volume 38. Signum-Verlag, Hamburg. Mittelmark, M.B. and Bauer, G.F. (2017) The Meanings of Salutogenesis. In Mittelmark, M.B., Sagy, S., Eriksson, M., Bauer, G.F., Pelikan, J.M., Lindström, B. and Espnes, G.A. (eds), The Handbook of Salutogenesis. Springer, New York, NY, 7-13.

Oleson, B.R. and Jansbøl, K. (2005) Experiences from People with Deafblindness - a Nordic Project. Information Center for Acquired Deafblindness, Herlev, Denmark.

Padgett, D. (2008) Qualitative Methods in Social Work Research. Sage, London.

Pruchno, R., Heid, A.R. and Genderson, M.W. (2015) Resilience and Successful Aging: Aligning Complementary Constructs Using a Life Course Approach. Psychological Inquiry, 26, 200-207. 
Regmi, K., Naidoo, J. and Pilkington, P. (2010) Understanding the processes of translation and transliteration in qualitative research. International Journal of Qualitative Methods, 9, 16-26.

Robertson, J. and Emerson, E. (2010) Estimating the number of people with co-occurring vision and hearing impairments in the UK. Centre for Disability Research, Lancaster.

Schröder-Butterfill, E. and Marianti, R. (2006) A framework for understanding old-age vulnerabilities. Ageing and Society, 26, 9-35.

Schwartz, S. (2008) Tactile sign language corpora: capture and annotation issues. In Language Resources and Evaluation Conference: 3rd Workshop on the Representation and Processing of Signed Languages: Construction and Exploitation of Sign Language Corpora. Marrakech, Morrocco, 170-173.

Shinebourne, P. (2011) Interpretative Phenomenological Analysis. In Frost, N. (ed), Qualitative Research Methods in Psychology: Combining core approaches. Open University, Maidenhead, 44-65.

Simcock, P. (2017a) Ageing with a unique impairment: a systematically conducted review of older deafblind people's experiences. Ageing \& Society, 37, 1703-1742. Simcock, P. (2017b) One of society's most vulnerable groups? A systematically conducted literature review exploring the vulnerability of deafblind people. Health and Social Care in the Community, 25, 813-839.

Simcock, P. (2020) The Lived Experience of Vulnerability among Adults Ageing with Deafblindness: an Interpretative Phenomenological Analysis. Unpublished PhD Thesis. King's College London, London.

Simcock, P. and Manthorpe, J. (2020) Ageing with Deafblindness In Putnam, M. and Bigby, C. (eds), Handbook of Ageing with Disability. Routledge, New York, 97-107. Simcock, P. and Wittich, W. (2019) Are older deafblind people being left behind? A narrative review of literature on deafblindness through the lens of the United Nations Principles for Older People. Journal of Social Welfare and Family Law, 41, 339-357. Smith, J., Flowers, P. and Larkin, M. (2009) Interpretative Phenomenological Analysis. Theory, Method and Research. Sage, London.

Squires, A. (2009) Methodological Challenges in Cross-Language Qualitative Research: A Research Review. International Journal of Nursing Studies, 46, 277-287.

Tarzia, L., Bauer, M., Fetherstonhaugh, D. and Nay, R. (2013) Interviewing Older People in Residential Aged Care About Sexuality: Difficulties and Challenges. Sexuality and Disability, 31, 361-371.

Thurairajah, K. (2019) Uncloaking the Research: Boundaries in Qualitative Research. Qualitative Sociology Review, 15, 132-147.

UyBico, S., Pavel, S. and Gross, C. (2007) Recruiting Vulnerable Populations into Research: A Systematic Review of Recruitment Interventions. Society of General Internal Medicine, 22, 852-863.

Wadsworth, Y. (1984) Do it Yourself Social Research. Victorian Council of Social Services, Melbourne.

Westwood, S. and Carey, N. (2018) Ageing with Physical Disabilities and/or Long-Term Health Conditions. In Westwood, S. (ed), Ageing, Diversity and Equality: Social Justice Perspectives: Social Justice Perspectives. Routledge, Oxon, 225-244.

Wittich, W. and Simcock, P. (2019) Aging and Combined Vision and Hearing Loss. In Ravenscroft, J. (ed), The Routledge Handbook of Visual Impairment. Routledge, London, 438-451.

Young, A., Ferguson-Coleman, E. and Keady, J. (2014) Understanding the personhood of Deaf people with dementia: Methodological issues. Journal of Aging Studies, 31, 62-69. 
Young, A. and Temple, B. (2014) Approaches to Social Research: The Case of Deaf Studies. Oxford University Press, Oxford. 
Table One: Inclusion and Exclusion Criteria for Participation.

\begin{tabular}{|c|c|}
\hline Inclusion Criteria: & Exclusion Criteria: \\
\hline $\begin{array}{l}\text { Deafblind as defined by the Department of } \\
\text { Health }(1997 ; 2017) \text {. }\end{array}$ & Non-deafblind or single sensory impaired \\
\hline $\begin{array}{l}\text { Deafblind from birth (congenital) or } \\
\text { deafblind for the majority of adult life } \\
\text { (acquired in childhood or early adulthood). }\end{array}$ & Has late life acquired deafblindness. \\
\hline 48 years of age or older. & Under 48 years of age. ${ }^{*}$ \\
\hline $\begin{array}{l}\text { Has capacity to give informed consent to } \\
\text { participate in the research (as defined under } \\
\text { the Mental Capacity Act 2005). }\end{array}$ & $\begin{array}{l}\text { Unable to give informed consent for } \\
\text { himself/herself; lacks mental capacity to } \\
\text { make a decision about participation. }\end{array}$ \\
\hline $\begin{array}{l}\text { Able to offer a rich and detailed first-person } \\
\text { account of lived experience. }\end{array}$ & $\begin{array}{l}\text { Unable to offer a sufficiently rich and detailed } \\
\text { account of lived experience owing to a level } \\
\text { of learning disability and/or mental health } \\
\text { difficulties. }\end{array}$ \\
\hline $\begin{array}{l}\text { Health status is such that they are able to } \\
\text { participate in interviews. }\end{array}$ & $\begin{array}{l}\text { Acutely unwell (mentally or physically) such } \\
\text { that they are unable to participate in } \\
\text { interviews or where participation would be } \\
\text { detrimental to health. }\end{array}$ \\
\hline $\begin{array}{l}\text { Communicates in English, Visual British Sign } \\
\text { Language, tactile British Sign Language or via } \\
\text { deafblind manual or block alphabet. }\end{array}$ & $\begin{array}{l}\text { Communicates using language other than } \\
\text { English, or sign language or tactile sign } \\
\text { language from another country (i.e. not } \\
\text { British Sign Language). }\end{array}$ \\
\hline Live in England (in any setting). & Does not live in England. \\
\hline $\begin{array}{l}\text { Not known to the researcher in his previous } \\
\text { role as a specialist social worker. }\end{array}$ & $\begin{array}{l}\text { Known to the researcher in his previous role } \\
\text { as a specialist social worker. }\end{array}$ \\
\hline
\end{tabular}

* The lower age limit was originally set at 50 years of age. One participant was 48 years old at the time he expressed an interest in taking part. This triggered a review of the inclusion-exclusion criteria and the lower age limited was amended. 
Table Two: Participants' Language and Communication Methods

\begin{tabular}{|c|c|c|c|}
\hline $\begin{array}{l}\text { Participant } \\
\text { Pseudonym } \\
\text { and Age }\end{array}$ & $\begin{array}{c}\text { Aetiology of } \\
\text { Deafblindness }\end{array}$ & $\begin{array}{c}\text { Expressive Language } \\
\text { and/or } \\
\text { Communication } \\
\text { Method used }\end{array}$ & $\begin{array}{c}\text { Receptive Language } \\
\text { and/or } \\
\text { Communication } \\
\text { Method used }\end{array}$ \\
\hline $\begin{array}{l}\text { Mike } \\
58\end{array}$ & Usher Type II & Speech (English) & $\begin{array}{l}\text { Accesses speech using } \\
\text { residual hearing and } \\
\text { hearing aids } \\
\text { Deafblind Manual }\end{array}$ \\
\hline $\begin{array}{l}\text { Celia } \\
83\end{array}$ & Usher Type I & British Sign Language & $\begin{array}{l}\text { Tactile British Sign } \\
\text { Language* } \\
\text { Deafblind Manual } \\
\text { (Interpreter facilitated) }\end{array}$ \\
\hline $\begin{array}{l}\text { Faye } \\
52\end{array}$ & Usher Type II & Speech (English) & $\begin{array}{l}\text { Accesses speech using } \\
\text { residual hearing and } \\
\text { hearing aids }\end{array}$ \\
\hline $\begin{array}{l}\text { Matthew } \\
48\end{array}$ & $\begin{array}{l}\text { Congenital } \\
\text { Rubella } \\
\text { Syndrome }\end{array}$ & Speech (English) & $\begin{array}{l}\text { Accesses speech using } \\
\text { residual hearing and } \\
\text { hearing aids }\end{array}$ \\
\hline $\begin{array}{l}\text { Phillip } \\
58\end{array}$ & Usher Type III & Speech (English) & $\begin{array}{l}\text { Accesses speech using } \\
\text { residual hearing and } \\
\text { hearing aids }\end{array}$ \\
\hline $\begin{array}{l}\text { Anthony } \\
73\end{array}$ & Usher Type I & British Sign Language & $\begin{array}{l}\text { Tactile British Sign } \\
\text { Language* }^{*} \\
\text { Deafblind Manual } \\
\text { (Interpreter facilitated) }\end{array}$ \\
\hline $\begin{array}{l}\text { Rose } \\
71\end{array}$ & $\begin{array}{l}\text { Congenital } \\
\text { Rubella } \\
\text { Syndrome }\end{array}$ & Speech (English) & $\begin{array}{l}\text { Accesses speech using } \\
\text { residual hearing and } \\
\text { hearing aids }\end{array}$ \\
\hline $\begin{array}{l}\text { Caroline } \\
67\end{array}$ & Usher Type II & Speech (English) & $\begin{array}{l}\text { Lip-reading and } \\
\text { accesses speech using } \\
\text { residual hearing and } \\
\text { hearing aids. }\end{array}$ \\
\hline
\end{tabular}

*Tactile British Sign Language, also known as 'hands-on' British Sign Language is an adapted form of BSL used by some deafblind people. The recipient places their hands over those of the signer, in order to feel rather than see the signs made. 